\title{
Review Article \\ Outcome Measures for Dementia in the Advanced Stage and at the End of Life
}

\author{
Ladislav Volicer ${ }^{1}$ and Jenny T. van der Steen ${ }^{2}$ \\ ${ }^{1}$ School of Aging Studies, University of South Florida, 4202 E. Fowler Avenue, Tampa, FL 33620, USA \\ ${ }^{2}$ Department of General Practice \& Elderly Care Medicine, EMGO Institute for Health and Care Research, \\ VU University Medical Center, Amsterdam, The Netherlands \\ Correspondence should be addressed to Ladislav Volicer; lvolicer@usf.edu
}

Received 2 March 2014; Accepted 14 July 2014; Published 21 August 2014

Academic Editor: Stavros Baloyannis

Copyright (C) 2014 L. Volicer and J. T. van der Steen. This is an open access article distributed under the Creative Commons Attribution License, which permits unrestricted use, distribution, and reproduction in any medium, provided the original work is properly cited.

\begin{abstract}
Increasing life span and lack of medication for prevention or treatment of progressive dementias will significantly increase the number of individuals with advanced dementia worldwide. Providing optimal care for them will stretch health care resources and will require evaluation of different treatment strategies. This paper is presenting measures that may be used in this patient population. Evaluation of global goals of palliative care may include measuring quality of life by QUALID scale, comfort by DSDAT scale, and engagement by MPES scale. Symptom control may be achieved by measuring pain by PAINAD or PACSLAC scales, by evaluating behavioral symptoms and their management (agitation by SOAPD scale, apathy by AES scale and rejection of care by RTC-DAT scale), and by monitoring patients for dyspnea using RDOS scale. Outcomes of palliative care at the end of life may be evaluated by EOLD-CAD scale and by determining family satisfaction with care (EOLD-SWC). Items included in these scales, psychometric properties, and research use of these scales are described. It is hoped that information in this paper will stimulate research interest in this important area.
\end{abstract}

\section{Background}

The authors of this review both enjoy international collaboration and started working together almost 20 years ago when they discovered that they have a common concern for persons with advanced dementia. The collaboration started by sharing scales that can be used for research in population. Initially, U.S. discomfort and dementia staging scales were used in Dutch studies that investigated treatment of pneumonia [13]. The Dutch translation of these scales was evaluated and additional work assessed a cut off for severe dementia [4] and the staging of the items [5] and the Dutch investigators also evaluated a new U.S. set of scales for dementia at the end of life [6]. Recent work developed also from sharing newly collected [3] and existing data [7] - the Dutch author analyzing the U.S. data and vice versa. Where previous work focused on pneumonia, newer work was on modifiable factors that are increasing risk of behavioral symptoms of dementia [7]. The common theme in this research was concern for quality of life of person with advanced dementia that could be supported by palliative care, as summarized in recent work defining domains and recommendations for palliative in dementia [8].

The authors share a belief that barriers to performing high-quality research in this population can be overcome, and one important barrier was the lack of outcome measures with optimal psychometric properties specific for this population. The importance of measuring outcomes at the end of life in persons with dementia is increased by three factors. The first one is increasing longevity that exposes more people to the risk of development of dementia. The second factor is failure of several medications that were developed to stop progression or cure Alzheimer's disease, the most common cause of dementia. Development of these drugs was based on the amyloid hypothesis tested in a transgenic mouse model and their failure may indicate that the hypothesis does not apply in most persons with Alzheimer's disease [9]. Therefore, although other avenues are also being investigated, there is no effective drug that would prevent or cure Alzheimer's disease 
on the horizon and the number of persons who are dying with dementia is going to increase significantly.

The third factor is recognition that current strategies for treatment of persons with dementia at the end of life may not be optimal. Some care providers may not consider that most causes of dementia are progressive and ultimately terminal diseases. However, there is also a need to treat chronic diseases and intercurrent diseases (e.g., pneumonia) that may cause discomfort and bothersome symptoms. A need for improvement of care for persons with advanced dementia is being recognized and an example of this effort is the movement to change the culture of care for persons with dementia and make it person centered which was recently introduced [10]. All introduced changes should be carefully investigated to assure that they actually improve care.

Measuring quality of care is difficult in persons with advanced dementia who are nonverbal and cannot report how they feel. Caregivers are limited to infer the condition of persons with dementia from observation of their behaviors and nonverbal communications. However, these observations may be quite important because they may uncover physical or psychiatric conditions that require treatment or unmet needs of the person with dementia. Although experienced clinicians may be able to interpret their observations and implement proper measures, it may be helpful if the observations are guided by a formal strategy. Formal observations are, of course, necessary for conducting research in persons with advanced dementia and may form a scale that measures specific facet of dementia care. Several such scales were developed and used in research and this paper will describe some of them. We will discuss the background and properties of selected measures which we feel conceptually capture the most relevant outcomes in advanced dementia and at the end of life.

We first provide measures for assessment of global goals of palliative care in dementia; quality of life and absence of discomfort [8]. We also discuss assessment of engagement that is important for quality of life. The most important symptoms at the end of life with dementia are pain, shortness of breath, and behavioral symptoms $[11,12]$. We discuss measures for each of these symptoms, and regarding behaviors, we include social behaviors when discussing rejection of care and engagement. We conclude with satisfaction with care in the form of a family evaluation of care which is an important outcome at the end of life on its own [13].

\section{Evaluation of Global Goals of Palliative Care}

Global goals of palliative care include maintenance or improvement of quality of life. Quality of life is a very subjective concept because individuals may have different concepts of what is important for their quality of life. It is usually measured by directly asking the person but that is not possible in persons with advanced dementia. Therefore, measuring quality of life in these individuals is limited by observing them and interpreting their behavior, emotions and nonverbal communications. Important components of quality of life of persons with dementia are avoidance of discomfort and opportunity to engage in meaningful activities.
2.1. Quality of Life. A number of scales have been devised to measure quality of life in persons with severe dementia, but all except the QUALID [14] have a subjective component and floor effects. The Quality of Life in Alzheimer's Disease Scale [15] has been found useful only for persons with MiniMental State Examination (MMSE; [16]) scores $\geq 3$. The Cornell-Brown Scale for Quality of Life in Dementia [17], derived from the Cornell Scale for Depression in Dementia [18] is limited by its requirement of a joint interview of caregiver and patients and appears to be useful primarily with subjects having an MMSE score > 8. Use of the Quality of Life in Dementia scale (QUALIDEM; [19]) is restricted by its requirement for subjective information from patients and by the omitting of items for severe dementia.

The QUALID was designed to help assess the outcome of clinical management and treatment on quality of life in persons with late-stage dementia residing in long-term care facilities [14]. The QUALID employs a questionnaire administered by a trained technician or research nurse (recorder) to professional caregivers (physicians or nurses) who must have had at least 30 hours of exposure to the resident during the previous week. The recorder conducts a structured interview with the professional caregivers (nurses, aides) who infer patients' state of mind and level of physical or emotional comfort or discomfort. The QUALID has a one-week window of observation. The items, which are all based on observable behaviors, rated on a 5-point scale, are presented in Table 7.

The QUALID scale has good internal consistency testretest reliability and interrater reliability $(\mathrm{ICC}=0.8)$. The QUALID scale is sensitive to effects of medications and its use found that subjects who were receiving neuroleptic or antidepressant medications were found to have significantly lower (better) QUALID scores. The QUALID has been translated from English to Finnish, Spanish, Swedish, German, Dutch, Estonian, and Italian but has been published only in English, Spanish [20], Dutch [21], and Swedish [22]. An English form is available free online at http://www.dementia-assessment.com.au/quality/QUALID_Instructions_scale.pdf but does not include instructions. It is also available (with instructions) for subscribers to the American Psychological Association's psycTESTS at http://www.apa.org/pubs/databases/psyctests/index.aspx. Finally, the QUALID is available (with instructions and at no charge) from myronweiner@yahoo.com.

2.2. Comfort. Comfort can be defined in three ways: (1) relief from discomfort, the experience of a person who has had specific needs met, (2) ease, a state of calm or contentment, and (3) transcendence, being strengthened or invigoratedthe state in which persons rise above their problems or challenges [23]. These three ways occur in four contexts: (1) physical, bodily sensations, (2) social, interpersonal, family, and societal relationships, (3) psychospiritual, internal awareness of self, including self-esteem, self-concept, sexuality, and meaning in one's life and also one's relationship to a higher order or being, and (4) environmental, external background of human experience, that include light, noise, ambience, color, temperature, and natural versus synthetic elements. In 
advanced dementia and at the end of life, comfort is best determined by absence of discomfort.

Discomfort Scale for Dementia of the Alzheimer Type (DS-DAT) [24] was developed on the basis of interviews with experienced nurses who cared for persons with dementia. Discomfort was defined as a negative emotional and/or physical state in response to internal or environmental conditions. The DS-DAT has nine items that are made operational by 40 defining characteristics (Table 2). Items are scored 0,1 , 2 , or 3 depending on the number of defining characteristics present and their intensity and duration during a 5-minute observation period. When items cannot be observed; for example, a patient with shut eyes could not be rated for a sad facial expression, the item is scored as NA (not applicable) and recoded to "0." The two positively worded items are reverse coded. Then item's scores are summed to provide a total score. High scores mean high levels of observed discomfort. The research observer must know all the defining characteristics of each item.

A review of DS-DAT [25] found that several studies have demonstrated acceptable reliability and validity of the scale including retrospective assessments. The DS-DAT can be regarded a classical instrument, based on which several other instruments for more narrow concepts such as pain and resistiveness to care have been developed. The scale has been used in research, the original version as well as several modifications.

DS-DAT has very good psychometric properties with excellent internal consistency and factor analyses indicating that it measures a single concept. Furthermore, discomfort is moderately associated with acute illness. DS-DAT has also good interobserver and intraobserver reliability [26]. It has been used in several research projects in the United States, Italy, and the Netherlands. While PAINAD can be used easily in daily clinical practice, DS-DAT is mainly used for research because it requires extensive training of the observers and the period of observation is longer.

2.3. Engagement. Persons with dementia develop inability to independently engage in meaningful activities because of a deficit of executive function and cognitive impairment. Therefore, to maintain their quality of life and prevent development of behavioral symptoms of dementia (e.g., agitation and pacing), they have to be provided with an opportunity to engage in meaningful activities. These activities have to be adjusted according to previous interests of a person with dementia and severity of dementia. Activities are designed to capture the attention and to promote positive interactions of persons with dementia with the environment.

The Menorah Park Engagement Scale (MPES) was developed in conjunction with the development of MontessoriBased Dementia Programming-MBDP [27, 28] (Table 6). Montessori education is an educational approach originally developed for children by Italian physician and educator Maria Montessori. It is characterized by an emphasis on independence, freedom within limits, and respect for a child's natural psychological, physical, and social development. In the Montessori method, task breakdown, guided repetition, progressions from simple to complex and concrete to abstract, and the like are inherent in educational activities for children. Montessori-based programming adapted for persons with dementia takes advantage of principles used in dementia interventions, including extensive use of external cues and reliance on procedural or implicit memory rather than declarative or explicit memory. Implicit memory is both unconscious and unintentional and includes procedural memories, such as how to perform a specific task like swinging a baseball bat or making toast. While implicit memories are not consciously recalled, they still have an influence on behavior as well as knowledge of different tasks. Therefore, people with advanced dementia may still remember how to do activities that include for instance sorting of pictures according to labeled categories or names, sorting of buttons or poker chips, or how to open mouth when approached with a spoon and may be even able to learn these activities [29].

MPES is available in two versions; the general MPES form designed to be used in research projects and the brief MPES form designed to be used by staff members of programs or residences serving persons with dementia to enable them to easily document effects of activities provided to persons with dementia. The general MPES should be used in research projects targeted to explore nonpharmacological interventions for problematic or undesirable responsive behaviors, as well as to document proximal and distal effects of producing positive engagement. MPES is sensitive to measure effects of quality activity programming and captures the presence of altruism in persons with dementia during activities (helping others), as well as documenting the presence or absence of problematic behaviors during activities.

The observational measurement of engagement assessment (OME) was developed by Cohen-Mansfield and her colleagues [30]. OME data are gathered through direct observation and entered onto a handheld computer with special software developed for this purpose. Outcome variables on the OME are duration-time in which the participant is engaged with the stimulus, attention to the stimulus, and attitude to the stimulus. MPES has some advantages over OME because it does not require either hardware or specialized software to obtain data and focuses on different forms or aspects of engagement and thus can track transitions in engagement, such as observing a person go from being asleep to being awake-but not focused on a target activity, or to watching a target activity, or to actively taking part in a target activity. However, both of these scales require further validation.

\section{Evaluation of Symptom Control}

3.1. Pain. A significant number of patients with advanced dementia and at the end of life have pain [11]. Comfort is often diminished or changed into discomfort if the individual perceives pain. Although pain is not the main symptom of dementia, persons with dementia often have pain because of chronic conditions, for example, arthritis, or intercurrent diseases, for example, urinary tract infection [31]. Very few if any patients with advanced dementia progress into a persistent vegetative stage [32] and, therefore, they can 
TABLE 1: Pain assessment in advanced dementia (PAINAD).

\begin{tabular}{l}
\hline Items \\
\hline Breathing independent of vocalization \\
Negative vocalization \\
Facial expression \\
Body language \\
Consolability
\end{tabular}

For scoring see Warden et al., 2003 [44].

still perceive pain. Pain perception is not diminished in Alzheimer's disease but may be actually increased because patients perceive their pain for a longer time [33]. While neither stimulus detection nor pain threshold is correlated to cognitive status in Alzheimer's disease, the vegetative response is lower in more advanced disease [34] but facial responses to noxious stimulation are increased when compared to cognitively intact individuals [35]. However, pain perception may vary according to the type of dementia. Persons with frontotemporal dementia may have an increased pain threshold and pain tolerance [36].

Detection and diagnosis of pain in residents with advanced dementia is one of the most important factors in their total care. Nurses may feel highly uncertain about pain in residents with dementia who could not report if they were in pain [37]. Patients with advanced dementia are less likely to have the ability to respond to pain scales, necessitating the use of observational scales in up to about half of patients (31\%; [38]; 53\%; [39]). More than half of residents who were dying with advanced dementia experienced pain in the last week of life that was not satisfactorily managed $[40,41]$. The prevalence of pain increases to $80 \%$ if rare pain is included [11].

Several observational scales for measuring pain in noncommunicative patients were developed and recently compared by The City of Hope Pain and Palliative Care Resource Center (http://prc.coh.org/PAIN-NOA.htm) and by Herr et al. [42, 43]. The comparison criteria included conceptualization, subjects and setting of the validation papers, ease of administration and scoring, feasibility, reliability, and validity. The scale with the highest overall score was Pain Assessment in Advanced Dementia (PAINAD) [44] (Table 1). PAINAD has good internal consistency and very good interrater reliability. It has very good concurrent validity when compared with other pain scales. It has also very good discriminant validity because it is able to distinguish effect of analgesics and difference between various severities of pain. PAINAD was translated into 10 languages and is widely used for both clinical and research purposes. An instructional online video is available that shows nurses using PAINAD at http://links.lww.com/A251. Another good scale according to the same sources is PACSLAC, (http://prc.coh.org/PAINNOA.htm) and by Herr et al. $[42,43]$ but it includes 60 items [45] and some items are not observed in a few minutes, such as "change in eyes" and "increased confusion" which require prior familiarity with the patient's behavior.
TABLE 2: Discomfort scale-dementia of the Alzheimer type (DSDAT).

\begin{tabular}{l}
\hline Items \\
\hline Noisy breathing \\
Negative vocalization \\
Content facial expression* \\
Sad facial expression \\
Frightened facial expression \\
Frown facial expression \\
Relaxed body language \\
Tense body language \\
Fidgeting body language
\end{tabular}

${ }^{*}$ reverse coded for calculation of total score.

For scoring see Hurley et al., 1992 [24].

3.2. Behavioral Symptoms of Dementia. Management of behavioral symptoms in persons with dementia is as important as management of pain in patients with cancer. Behavioral symptoms may appear even before diagnosis of dementia and increase with dementia progression. Initially, there may be differences in behavioral symptoms in different types of dementia but in advanced stages all persons with progressive dementias exhibit similar symptoms. Although persons with dementia may show several types of behavioral symptoms and one scale using caregiver reports includes 29 items [46], there are three main behavioral syndromes that are disturbing for the persons with dementia and/or their caregivers: agitation, apathy, and rejection of care.

Unfortunately, there is a confusion regarding terminology of behavioral symptoms of dementia. An example is mislabeled area "agitation/aggression" of the Neuropsychiatric Inventory that is being considered as a gold standard for evaluation of behaviors in persons with dementia. The probing questions for "agitation/aggression" are "does the resident have periods when he/she refuses to let people help him/her? Is he/she hard to handle? Is he/she noisy or uncooperative? Does the resident attempt to hurt or hit others?" These questions clearly ask if the resident rejects care while interacting with a caregiver. Agitation defined below is probably captured by the NPI area "aberrant motor behavior" although this area does not include disruptive vocalization [47].

Another problem is with the term aggression. What is aggression? According to the Merriam Webster Dictionary aggression is "a forceful action or procedure as an unprovoked attack." Wikipedia states that "aggression is an intention to cause harm or an act intended to increase relative social dominance." There is no reason to believe that persons with dementia intend to cause harm or increase social dominance. Actually, the behavior that some people call "aggression" is almost always a result of rejection of care that escalates into combative behavior [7]. Labeling persons with dementia "aggressive" is blaming the victim, because persons with dementia most often reject care when they cannot understand why a caregiver is approaching them. They may consider the caregiver to be an aggressor and defend themselves against 
TABle 3: Scale for Observation of Agitation in Persons with DAT [dementia of the Alzheimer type] (SOAPD).

\begin{tabular}{l}
\hline Total body movements \\
Up and down movements \\
Repetitive movements in place \\
Mild \\
Moderate \\
Extreme \\
Outward motions \\
Mild \\
$\quad$ Moderate \\
Extreme \\
High pitched or loud words \\
Repetitive vocalization \\
Negative words
\end{tabular}

For scoring see Hurley et al., 1999 [49].

this unwanted intrusion. It would improve clinical usefulness of research studies if they used the same terminology as the clinicians who are evaluating persons with dementia. Therefore, we would like to propose that the term "aggression" should be reserved to the few persons with dementia who actually may strike out without any provocation.

3.2.1. Agitation. Some clinicians and researchers may mislabel all behavioral symptoms of dementia as "agitation." Use of this terminology does not take into consideration the circumstances in which behaviors occurred and makes it more difficult to develop strategies for dealing with these behaviors. We believe that the term "agitation" should be reserved for behaviors that occur when the person with dementia is solitary and is not elicited by an outside stimulus, for example, periods of restlessness, repetitive physical movements, wandering, and socially inappropriate/disruptive behavior [48]. Agitation in this narrower sense can be defined as those behaviors that communicate to others [who observe the patient] that the person with dementia... is experiencing an unpleasant state of excitement and are [sic] observable without subjective interpretation, are not behaviors that are invoked by caregiving activities, are unrelated to known physical needs of the patient that can be remedied, and are without known motivational intent [49].

Based on this concept, the Scale for Observation of Agitation in Persons with DAT [dementia of the Alzheimer type] (SOAPD) was developed [49]. SOAPD consists of 7 items (Table 3). Three different levels of intensity are built into the definition of 2 items, so the scoring option is presence or absence, and if present, then the item was scored for intensity and duration. The remaining 5 items (if present) are scored only for duration. Scores for individual items are weighted by numbers developed by the Magnitude estimate scaling (MES). MES is the process of assigning numbers proportionally to stimuli that reflect the intensity of response [50]. The MES process of weighting resulted in scores that ranged from 36.5 for mild outward motions with a short duration to 787.3 for high/loud vocalization with a long duration. The theoretic range of the SOAPD is $0-4,445.3$.

The SOAPD has been well defined conceptually and operationally, has excellent psychometric properties, and is easy to use. SOAPD was used only in one study [51] but the definition of agitation used in the SOAPD was cited in a concept clarification article as marking the transition from the observer's perspective to the patient's perspective in the interpretation of agitation [52].

Other scales that are sometimes used for measurement of agitation include the Neuropsychiatric Inventory (NPI) [53] and the Behavioral Pathology in Alzheimer's Disease Rating Scale (BEHAVE-AD) [54]. Although they were recommended for the assessment of behavioral disturbances associated with dementia [55], these scales do not use the concept of agitation described above. One of the areas of the NPI scale is labeled "agitation/aggression" but the probing questions are "does the patient have periods when he/she refuses to cooperate or won't let people help him/her? Is he/she hard to handle?" Therefore, this area really measures rejection of care and not agitation [47]. Similarly, BEHAVE$\mathrm{AD}$ is confusing agitation and rejection of care because one of the defining characteristics of agitation is "refusal to bathe, dress, or take medication".

3.2.2. Apathy. Apathy can be described as a lack of interest or emotion [56]. It may be the first symptom of cognitive impairment, especially in the frontotemporal dementia. Apathy has been recognized recently as a common psychiatric syndrome in the elderly with prevalence ranging from 32 to 93\% [56]. Prevalence of apathy increases with the severity of dementia. Apathy is different from depression although apathy and depressive symptoms may occur simultaneously. Analysis of Minimum Data Set (MDS) of 1669 Dutch nursing home residents showed that apathy and symptoms of depression coexisted in $26.9 \%$ of the residents [57]. Apathy and depressive symptoms responded differently to a multidisciplinary treatment program that included activating strategies, psychotherapy, and medication [58]. While apathy responded to activating strategies, symptoms of depression responded mainly to psychotherapy. The difference between apathy and depression is also supported by worsening of apathy caused by antidepressant treatment $[59,60]$.

Apathy is one of the behavioral areas than can be measured by the NPI [53]. Another scale commonly used for measuring apathy is Apathy Evaluation Scale (AES) [61]. This scale had originally 18 items and was more recently abbreviated to 10-item AES [62] (Table 4). AES-10 correlated highly with the original scale and its internal consistency was even higher than consistency of the original scale. Correlations with indicators of convergent (NPI Apathy) and discriminant validity (NPI Depression) remained nearly unchanged in the reduced 10 -item scale when compared to the original version. Correlations with cognitive aspects and global severity of dementia were reduced in the AES-10 when compared to the original scale indicating that AES-10 is a more refined scale that was less confounded by cognitive aspects of dementia [62]. Presence of apathy may also be obtained from the MDS that contains two items: withdrawal 
TABLE 4: Abbreviated Apathy Evaluation Scale (AES-10).

S/he is interested in things

S/he gets things done during the day

Getting things started on his/her own is important to her/him

$\mathrm{S} /$ he is interested in having new experiences

S/he puts little effort into anything

S/he approaches life with intensity

Seeing a job through to the end is important to her/him

$\mathrm{He} /$ she spends time doing things that interest her/him

$\mathrm{S} /$ he has initiative

S/he has motivation

For scoring see Lueken et al., 2007 [62].

from activities of interest and reduced social interaction [48].

3.2.3. Rejection of Care. Terminology of behavioral symptoms of dementia is developing and changing with our emphasis on patient-centered care. This is documented by changes from MDS 2.0 to MDS 3.0 where "resist care" is changed to "reject care that is necessary to achieve the resident's goals for health and wellbeing." Similarly, "abusive behavior" was changed to "behavioral symptoms directed toward others" to avoid pejorative labeling of the resident. Rejection of care is caused by two main factors: lack of understanding by the person with dementia of caregivers' intents and by depression [7]. Because the person with dementia does not understand the need for care, he/she does not cooperate with the caregiver and may actually actively resist caregiver's attempts to provide care. If the caregiver persists in trying to provide care, person with dementia may become combative and may be called "abusive." In addition, depression may cause "abusive behavior" even in absence of rejection of care.

Rejection of care may be defined as behavior that "reject(s) evaluation or care (e.g., blood work, taking medications, and activity of daily living [ADL] assistance) that is necessary to achieve the resident's goals for health and wellbeing" [60]. Rejection of care (RC) requires a patient's intent to refuse or reject the care, is not RC if patients' somnolence prevents them from swallowing medications, does not include aggressive behaviors with the underlying intent to harm others, and is not a disruptive behavior occurring outside of evaluation or caregiving activities. Prevalence of rejection of care increases with severity of dementia because of increased lack of understanding of caregiver's intent and may be present in up to $35 \%$ of nursing home residents [7].

Rejection of care can be evaluated by the NPI item "agitation/aggression" as explained above. An observational scale for measuring rejection of care was also developedResistiveness to Care-Dementia of the Alzheimer Type (RTCDAT) [63]. This scale consists of 13 items that are rated according to their duration and intensity during 5 minutes when a care is provided (Table 5). RTC-DAT has good content validity and excellent internal reliability.

TABLE 5: Resistiveness to care-dementia of the Alzheimer type (RTC-DAT) scale.

\begin{tabular}{lc}
\hline & Items \\
\hline Turn away & Hit/kick \\
Pull away & Say no \\
Push away & Cry \\
Push/pull & Threaten \\
Grab object & Scream/yell \\
Grab person & Clench mouth \\
Adduct & \\
\hline
\end{tabular}

For scoring Mahoney et al., 1999 [63].

TABle 6: Items of the Menorah Park Engagement Scale (MPES), general form.

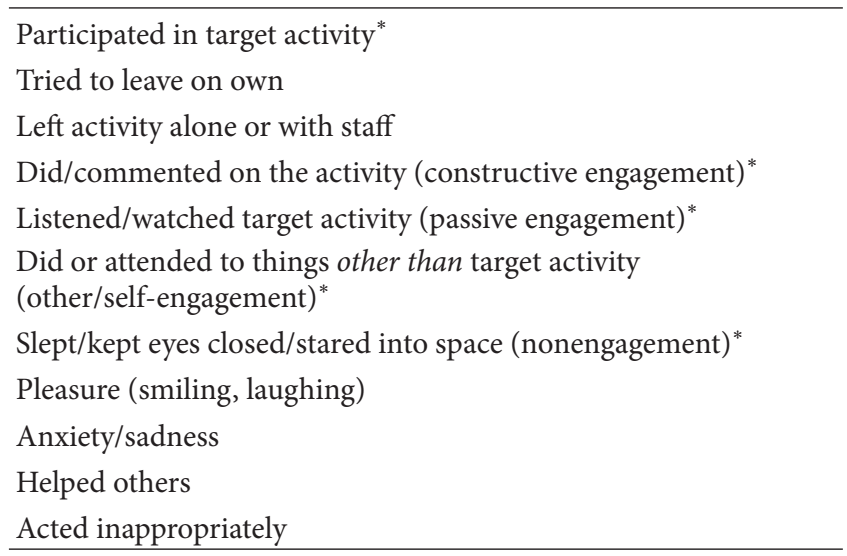

${ }^{*}$ Items included in the Brief Form of MPES.

TABLE 7: Items of quality of life in late stage dementia scale (QUALID).

Smiles

Appears sad

Cries

Has facial expression of

discomfort

Appears physically

uncomfortable

Verbalizations express

discomfort

For further information see Weiner et al., 2000 [14].

3.3. Respiratory Distress. Shortness of breath is quite common at the end of life with dementia and may be one of the most disturbing symptoms. Since patients with advanced dementia may not be able to provide self-report about distress from dyspnea, they are vulnerable to underrecognition and undertreatment. Although "shortness of breath" is an item in EOLD-CAD, it may be useful to evaluate this symptom in more detail. RDOS was developed based on evidence of activation of fear center (amygdala) by an asphyxia threat and on presence of specific behaviors activated by pulmonary stress [64]. 
The Respiratory Distress Observation Scale (RDOS) has good internal consistency and its validity was documented by significant correlation with dyspnea visual analog scale and with peripheral oxygen saturation. In patients with pain, RDOS score correlated with numeric pain report and this correlation was due to presence of tachycardia. When heart rate was removed, there was no correlation between pain and RDOS scores. Discriminant validity of RDOS was documented by differences of RDOS scores between patients with dyspnea and pain [64].

\section{Evaluation of Outcomes of Palliative Care at the End of Life}

Currently, the care provided for persons with dementia at the end of life is less than optimal. In the United States, persons with dementia experience distressing symptoms (especially dyspnea and pain) during their last 3 months of life, and almost half of them are exposed to at least one burdensome intervention (hospitalization, emergency room visit, parenteral therapy, or tube feeding) [65]. The situation is not better in Europe where data from Belgium and the Netherlands indicate that persons with dementia experience pain, more than one quarter of them have pressure sores, and almost one quarter are physically restrained [11, 40]. According to the Stewart's overall conceptual model of factors affecting quality and length of life of dying patients and their families' outcomes of care include quality of life and satisfaction with care [13].

Three EOLD scales were developed based on responses of family caregivers of persons with dementia who died within the last year [66]. All items in the questionnaire asked for information related to the care recipient's last 90 days of life or to the care recipient's condition during the dying process. The scales were compared with other scales used with people with advanced dementia by [67]. We will list two of the three scales because the third, the EOLD-Symptom Management scale, did not perform well in this comparison.

4.1. Comfort Assessment in Dying with Dementia (EOLD$C A D)$. Maintenance of comfort during dying may be the most important factor for quality of lifer. Of the instruments measuring quality of dying, EOLD-CAD [68] and MiniSuffering State Examination (MSSE) [69] met more criteria than others, but EOLD-CAD performed better on content and construct validity than MSSE [6]. Questions in EOLDCAD were constructed using an array of the symptoms and conditions commonly observed during the dying process in persons with dementia [70] (Table 8). Factor analysis showed that the scale is composed of four factors: physical distress, emotional distress, wellbeing, and dying symptoms.

The EOLD-CAD is valid and satisfied all validity factors (prior relevant use, coherence of construct, convergent validity to overall rating and other instruments measuring the same construct, and factorial validity) [71]. Reliability is excellent for the whole scale and at least acceptable for individual subscales. Convergent validity of EOLD-CAD was supported by significant correlation with QUALID. EOLD
TABLE 8: Items in scales measuring quality of care at the end of life with dementia.

\begin{tabular}{|c|c|}
\hline $\begin{array}{l}\text { Comfort assessment in dying } \\
\text { with dementia (EOLD-CAD) }\end{array}$ & $\begin{array}{c}\text { Respiratory distress } \\
\text { observation scale (RDOS) }\end{array}$ \\
\hline Discomfort $^{1}$ & Heart rate \\
\hline Pain $^{1}$ & Respiratory rate \\
\hline Restlessness $^{1}$ & Restlessness \\
\hline Shortness of breath ${ }^{1,2}$ & Accessory muscle use \\
\hline Choking $^{2}$ & Grunting at end-expiration \\
\hline Gurgling $^{2}$ & Nasal flaring \\
\hline Difficulty swallowing $^{2}$ & Fearful facial expression \\
\hline \multicolumn{2}{|l|}{ Fear $^{3}$} \\
\hline \multicolumn{2}{|l|}{ Anxiety $^{3}$} \\
\hline \multicolumn{2}{|l|}{ Crying $^{3}$} \\
\hline \multicolumn{2}{|l|}{ Moaning $^{3}$} \\
\hline \multicolumn{2}{|l|}{ Serenity (inner peace) ${ }^{4}$} \\
\hline \multicolumn{2}{|l|}{ Peace $^{4}$} \\
\hline Calm $^{4}$ & \\
\hline
\end{tabular}

scales were used in two large projects investigating end of life in patients with dementia prospectively [65] and several publications resulted from these studies [66].

4.2. Satisfaction with Care. Satisfaction of family members with care provided to their relatives could be measured by End-Of-Life in Dementia-Satisfaction With Care (EOLDSWC) scale. The questions used for development of this scale were based on the MediCaring questionnaire addressing satisfaction with care [72]. Fifteen questions used a four point scale ranging from "strongly agree" (4) to strongly disagree (1) and included a "not applicable" selection. Negative questions were reverse-coded so that, for all responses, higher numbers represented more satisfaction. "Not applicable" responses were coded as "missing." Most items included were considered applicable by more than $94 \%$ of the respondents with the exception of one statement. This item also correlated strongly with another item and, therefore, it was deleted. Factor analysis showed that the scale consisted of only one factor. Four other items had high corrected item-total correlations $(r>0.8)$ and were deleted. The possible scores on this remaining 10 -item scale range from 10 to 40 with higher scores indicating more satisfaction.

EOLD-SWC had the highest rating regarding relevance and ease of use of the five scales measuring quality of care. Its validity was supported because it measured single construct and correlated highly with the Decision Satisfaction Inventory (DSI) $(r=0.81)$ [73], and with global assessment of care $(r=0.7)$. The scale is reliable with Cronbach alpha ranging from 0.83 to 0.9 . It was sensitive to detecting changes in health care proxies satisfaction with the care of residents when addressing whether the health care provider spent $>25$ minutes discussion the resident's advanced care planning, 
whether the physician counseled about the resident's life expectancy, whether resident resided in a special care unit, and whether the physician counseled possible resident health problems. Scores of EOLD-SWC exhibited a normal distribution and provide the opportunity to detect improvement in care strategies.

Perspectives. Observation of persons with advanced dementia provides rich information about their condition. Formation of scales based on these observations is important for research studying effects of various strategies for dementia care. It will be important to investigate how these scales could be useful in daily care. It will be important to document whether numeric scores improve communication between staff members, and between staff and families.

Another issue that requires further investigation is specificity of some of these scales. For instance, high PAINAD score may indicate not only presence of pain but also discomfort caused by other causes [74]. Different persons may respond to pain by different changes of behaviors and expressions which may allow for the assessment of pain or no pain, but not for pain intensity with these types of scales. However, use of scales that do not refer to previous conditions is needed because of the high turnover of caregivers for persons with dementia, and because some caregivers may not be familiar with the baseline state of the person and might have difficulties recognizing changes in their condition.

The measures in this review cover important outcomes of palliative care in dementia. However, at present scales are not available for all outcomes. For example, there is no scale for spiritual wellbeing specific to dementia. However, spiritual items (e.g., peace, which is also indicative of quality of care [75]) are included in the EOLD-CAD but developing a comprehensive measure of spiritual wellbeing may be challenging in advanced dementia. Most measures we discussed have been developed for, or validated in advanced dementia or dementia at the end of life specifically. However, some were not validated in this population, especially those addressing behavioral symptoms (e.g., apathy), and these scales need to be included in future research as relevant to advanced dementia and dementia at the end of life.

\section{Conflict of Interests}

The authors declare that there is no conflict of interests regarding the publication of this paper.

\section{References}

[1] J. T. van der Steen, M. E. Ooms, D. R. Mehr, G. van der Wal, and M. W. Ribbe, "Severe dementia and adverse outcomes of nursing home-acquired pneumonia: evidence for mediation by functional and pathophysiological decline," Journal of the American Geriatrics Society, vol. 50, no. 3, pp. 439-448, 2002.

[2] J. T. van der Steen, R. L. Kruse, K. L. Szafara et al., "Benefits and pitfalls of pooling datasets from comparable observational studies: combining US and Dutch nursing home studies," Palliative Medicine, vol. 22, no. 6, pp. 750-759, 2008.
[3] J. T. Van der Steen, P. Lane, N. W. Kowall, D. L. Knol, and L. Volicer, "Antibiotics and mortality in patients with lower respiratory infection and advanced dementia," Journal of the American Medical Directors Association, vol. 13, no. 2, pp. 156$161,2012$.

[4] J. T. van der Steem, L. Volicer, D. L. Gerritsen, R. L. Kruse, M. W. Ribbe, and D. R. Mehr, "Defining Severe dementia with the Minimum Data Set," International Journal of Geriatric Psychiatry, vol. 21, no. 11, pp. 1099-1106, 2006.

[5] F. Galindo-Garre, S. A. Hendriks, L. Volicer, M. Smalbrugge, C. M. Hertogh, and J. T. van der Steen, "The bedford Alzheimer nursing-severity scale to assess dementia severity in advanced dementia," The American Journal of Alzheimer's Disease and Other Dementias, vol. 29, no. 1, pp. 84-89, 2013.

[6] M. C. van Soest-Poortvliet, J. T. van der Steen, S. Zimmerman et al., "Selecting the best instruments to measure quality of endof-life care and quality of dying in long term care," Journal of the American Medical Directors Association, vol. 14, no. 3, pp. 179186, 2013

[7] L. Volicer, J. T. van der Steen, and D. H. M. Frijters, "Modifiable factors related to abusive behaviors in nursing home residents with dementia," Journal of the American Medical Directors Association, vol. 10, no. 9, pp. 617-622, 2009.

[8] J. T. van der Steen, L. Radbruch, C. M. Hertogh et al., "White paper defining optimal palliative care in older people with dementia: a Delphi study and recommendations from the European Association for Palliative Care," Palliative Medicine, vol. 28, no. 3, pp. 197-209, 2014.

[9] J. C. Morris, Persistent Failure of "Disease-Modifying" Drugs to Benefit Alzheimer Disease: Now What?, 2013.

[10] C. W. Hartmann, A. L. Snow, R. S. Allen, P. A. Parmelee, J. A. Palmer, and D. Berlowitz, "A conceptual model for culture change evaluation in nursing homes," Geriatric Nursing, vol. 34, pp. 388-394, 2013.

[11] S. A. Hendriks, M. Smalbrugge, C. M. P. M. Hertogh, and J. T. van der Steen, "Dying with dementia: symptoms, treatment, and quality of life in the last week of life," Journal of Pain and Symptom Management, vol. 47, no. 4, pp. 710-720, 2014.

[12] J. T. van der Steen, "Dying with dementia: what we know after more than a decade of research," Journal of Alzheimer's Disease, vol. 22, no. 1, pp. 37-55, 2010.

[13] A. L. Stewart, J. Teno, D. L. Patrick, and J. Lynn, “The concept of quality of life of dying persons in the context of health care," Journal of Pain and Symptom Management, vol. 17, no. 2, pp. 93 $108,1999$.

[14] M. F. Weiner, K. Martin-Cook, D. A. Vetlik, K. Saine, B. Foster, and C. S. Fontaine, "The quality of life in late-stage dementia (QUALID) scale," Journal of American Medical Directors Association, vol. 1, pp. 114-116, 2000.

[15] J. Hoe, C. Katona, B. Roch, and G. Livingston, "Use of the QOL-AD for measuring quality of life in people with severe dementia-the LASER-AD study," Age and Ageing, vol. 34, no. 2, pp. 130-135, 2005.

[16] M. Folstein, S. Folstein, and P. J. McHugh, “'Mini-mental State, a practical method for grading the cognitive state of patients for clinicians," Journal of Psychiatric Research, vol. 12, pp. 189-198, 1975.

[17] R. E. Ready, B. R. Ott, J. Grace, and I. Fernandez, "The CornellBrown Scale for quality of life in dementia," Alzheimer Disease and Associated Disorders, vol. 16, no. 2, pp. 109-115, 2002. 
[18] G. S. Alexopoulos, R. C. Abrams, R. C. Young, and C. A. Shamoian, "Cornell scale for depression in dementia," Biological Psychiatry, vol. 23, no. 3, pp. 271-284, 1988.

[19] T. P. Ettema, R. Dröes, J. De Lange, G. J. Mellenbergh, and M. W. Ribbe, "QUALIDEM: development and evaluation of a dementia specific quality of life instrument," International Journal of Geriatric Psychiatry, vol. 22, no. 6, pp. 549-556, 2007.

[20] G.-O. Josep, P.-P. Xènia, L.-P. Secundino et al., "Cross-cultural adaptation and psychometric validation of a Spanish version of the quality of life in late-stage dementia scale," Quality of Life Research, vol. 19, no. 3, pp. 445-453, 2010.

[21] D. Schalkwijk, L. R. Verlare, M. T. Muller, D. L. Knol, and J. T. van der Steen, "Measuring quality of life in nursing home residents with severe dementia: psychometric properties of the QUALID scale," Tijdschrift voor Gerontologie en Geriatrie, vol. 40, no. 5, pp. 184-192, 2009.

[22] H. Falk, L. Persson, and H. Wijk, "A psychometric evaluation of a Swedish version of the Quality of Life in Late-Stage Dementia (QUALID) scale," International Psychogeriatrics, vol. 19, no. 6, pp. 1040-1050, 2007.

[23] K. Y. Kolcaba, "A taxonomic structure for the concept comfort," Image, vol. 23, no. 4, pp. 237-240, 1991.

[24] A. C. Hurley, B. J. Volicer, P. A. Hanrahan, S. Houde, and L. Volicer, "Assessment of discomfort in advanced Alzheimer patients," Research in Nursing \& Health, vol. 15, no. 5, pp. 369377, 1992.

[25] J. T. van der Steen, M. J. Gijsberts, D. L. Knol, L. Deliens, and M. T. Muller, "Ratings of symptoms and comfort in dementia patients at the end of life: Comparison of nurses and families," Palliative Medicine, vol. 23, no. 4, pp. 317-324, 2009.

[26] L. I. Hoogendoorn, S. V. D. Kamp, C. A. Sheer Mahomed, H. J. Adèr, M. E. Ooms, and J. T. Van der Steen, "The role of the observer in the reliability of the Dutch Discomfort Scale-Dementia of Alzheimer Type (DS-DAT)," Tijdschrift voor Gerontologie en Geriatrie, vol. 32, no. 3, pp. 117-121, 2001 (Dutch).

[27] C. J. Camp, “The Menorah Park Engagement Scale (MPES) was developed in conjunction with the development of MontessoriBased Dementia Programming-MBDP," in Clinical Applied Gerontological Interventions in Long-Term Care, R. C. Intrieri and L. Hyer, Eds., pp. 295-314, Springer, New York, NY, USA, 2006.

[28] C. J. Camp, "Origins of montessori programming for dementia," Non-Pharmacologic Therapies in Dementia, vol. 1, no. 2, pp. 163$174,2010$.

[29] L. L. Eldridge, D. Masterman, and B. J. Knowlton, "Intact implicit habit learning in Alzheimer's disease," Behavioral Neuroscience, vol. 116, no. 4, pp. 722-726, 2002.

[30] J. Cohen-Mansfield, M. Dakheel-Ali, and M. S. Marx, "Engagement in persons with dementia: the concept and its measurement," The American Journal of Geriatric Psychiatry, vol. 17, no. 4, pp. 299-307, 2009.

[31] B. A. Ferrell, B. R. Ferrell, and L. Rivera, "Pain in cognitively impaired nursing home patients," Journal of Pain and Symptom Management, vol. 10, no. 8, pp. 591-598, 1995.

[32] L. Volicer, S. A. Berman, P. B. Cipolloni, and A. Mandell, "Persistent vegetative state in Alzheimer disease: does it exist?" Archives of Neurology, vol. 54, no. 11, pp. 1382-1384, 1997.

[33] L. J. Cole, M. Gavrilescu, L. A. Johnston, S. J. Gibson, M. J. Farrell, and G. F. Egan, "The impact of Alzheimer's disease on the functional connectivity between brain regions underlying pain perception," European Journal of Pain, vol. 15, no. 6, pp. 568.el-568.el1, 2011.

[34] F. Benedetti, C. Arduino, S. Vighetti, G. Asteggiano, L. Tarenzi, and I. Rainero, "Pain reactivity in Alzheimer patients with different degrees of cognitive impairment and brain electrical activity deterioration," Pain, vol. 111, no. 1-2, pp. 22-29, 2004.

[35] M. Kunz, V. Mylius, S. Scharmann, K. Schepelman, and S. Lautenbacher, "Influence of dementia on multiple components of pain," European Journal of Pain, vol. 13, no. 3, pp. 317-325, 2009.

[36] E. Carlino, F. Benedetti, I. Rainero et al., "Pain perception and tolerance in patients with frontotemporal dementia," Pain, vol. 151, no. 3, pp. 783-789, 2010.

[37] A. L. Gilmore-Bykovskyi and B. J. Bowers, "Understanding nurses' decisions to treat pain in nursing home residents with dementia," Research in Gerontological Nursing, vol. 6, no. 2, pp. 127-138, 2013.

[38] S. Pautex, A. Michon, M. Guedira et al., "Pain in severe dementia: self-assessment or observational scales?" Journal of the American Geriatrics Society, vol. 54, no. 7, pp. 1040-1045, 2006.

[39] S. M. G. Zwakhalen, R. T. C. M. Koopmans, P. J. E. M. Geels, M. P. F. Berger, and J. P. H. Hamers, "The prevalence of pain in nursing home residents with dementia measured using an observational pain scale," European Journal of Pain, vol. 13, no. 1, pp. 89-93, 2009.

[40] A. Vandervoort, L. Van den Block, J. T. van der Steen et al., "Nursing home residents dying with dementia in flanders, Belgium: a nationwide postmortem study on clinical characteristics and quality of dying," Journal of the American Medical Directors Association, vol. 14, no. 7, pp. 485-492, 2013.

[41] L. C. E. Pinzon, M. Claus, K. M. Perrar, K. I. Zepf, S. Letzel, and M. Weber, "Dying with dementia: symptom burden, quality of care, and place of death," Deutsches Arzteblatt International, vol. 110, no. 12, pp. 195-202, 2013.

[42] K. Herr, K. Bjoro, and S. Decker, "Tools for assessment of pain in nonverbal older adults with dementia: a state-of-the-science review," Journal of Pain and Symptom Management, vol. 31, no. 2, pp. 170-192, 2006.

[43] K. Herr, P. J. Coyne, M. McCaffery, R. Manworren, and S. Merkel, "Pain assessment in the patient unable to self-report: position statement with clinical practice recommendations," Pain Management Nursing, vol. 12, no. 4, pp. 230-250, 2011.

[44] V. Warden, A. C. Hurley, and L. Volicer, "Development and psychometric evaluation of the pain assessment in advanced dementia (PAINAD) scale," Journal of the American Medical Directors Association, vol. 4, no. 1, pp. 9-15, 2003.

[45] S. C. van Nispen tot Pannerden, M. J. J. M. Candel, S. M. G. Zwakhalen, J. P. H. Hamers, L. M. G. Curfs, and M. P. F. Berger, "An item response theory-based assessment of the pain assessment checklist for Seniors with Limited Ability to Communicate (PACSLAC)," Journal of Pain, vol. 10, no. 8, pp. 844-853, 2009.

[46] J. Cohen-Mansfield, M. S. Marx, and A. S. Rosenthal, "A description of agitation in a nursing home," Journals of Gerontology, vol. 44, no. 3, pp. M77-M84, 1989.

[47] L. Volicer, "What is NPI item "agitation/Aggression" really measuring?" American Journal of Geriatric Psychiatry, vol. 19, no. 12, p. 1046, 2011.

[48] D. L. Gerritsen, W. P. Achterberg, N. Steverink, A. M. Pot, D. H. M. Frijters, and M. W. Ribbe, "The MDS Challenging Behavior Profile for long-term care," Aging and Mental Health, vol. 12, no. 1, pp. 116-123, 2008. 
[49] A. C. Hurley, L. Volicer, L. Camberg et al., "Measurement of observed agitation in patients with dementia of the Alzheimer type," Journal of Mental Health and Aging, vol. 5, no. 2, pp. 117132, 1999.

[50] L. Sennott-Miller, C. Murdaugh, and A. S. Hinshaw, "Magnitude estimation: issues and practical applications," Western Journal of Nursing Research, vol. 10, no. 4, pp. 414-424, 1988.

[51] L. Camberg, P. Woods, W. L. Ooi et al., "Evaluation of simulated presence: a personalized approach to enhance well-being in persons with Alzheimer's disease," Journal of the American Geriatrics Society, vol. 47, no. 4, pp. 446-452, 1999.

[52] E. Kong, "Agitation in dementia: concept clarification," Journal of Advanced Nursing, vol. 52, no. 5, pp. 526-536, 2005.

[53] J. L. Cummings, M. Mega, K. Gray, S. Rosenberg-Thompson, D. A. Carusi, and J. Gornbein, "The neuropsychiatric inventory: comprehensive assessment of psychopathology in dementia," Neurology, vol. 44, no. 12, pp. 2308-2314, 1994.

[54] B. Reisberg, J. Borenstein, S. P. Salob, S. H. Ferris, E. Franssen, and A. Georgotas, "Behavioral symptoms in Alzheimer's disease: phenomenology and treatment," Journal of Clinical Psychiatry, vol. 48, supplement, pp. 9-15, 1987.

[55] Y. Jeon, J. Sansoni, L. Low, L. Chenoweth, S. Zapart, and N. Marosszeky, "Recommended measures for the assessment of behavioral disturbances associated with dementia," The American Journal of Geriatric Psychiatry, vol. 19, no. 5, pp. 403-415, 2011.

[56] S. Ishii, N. Weintraub, and J. R. Mervis, "Apathy: a Common Psychiatric Syndrome in the Elderly," Journal of the American Medical Directors Association, vol. 10, no. 6, pp. 381-393, 2009.

[57] L. Volicer, D. H. M. Frijters, and J. T. van der Steen, "Apathy and weight loss in nursing home residents: longitudinal study," Journal of the American Medical Directors Association, vol. 14, no. 6, pp. 417-420, 2013.

[58] R. Leontjevas, S. Teerenstra, M. Smalbrugge et al., "More insight into the concept of apathy: a multidisciplinary depression management program has different effects on depressive symptoms and apathy in nursing homes," International Psychogeriatrics, vol. 25, pp. 1941-1952, 2013.

[59] N. Wongpakaran, R. van Reekum, T. Wongpakaran, and D. Clarke, "Selective serotonin reuptake inhibitor use associates with apathy among depressed elderly: a case-control study," Annals of General Psychiatry, vol. 6, article 7, 2007.

[60] S. Ishii, J. E. Streim, and D. Saliba, "A conceptual framework for rejection of care behaviors: review of literature and analysis of role of dementia severity," Journal of the American Medical Directors Association, vol. 13, no. 1, pp. 11-23, 2012.

[61] R. S. Marin, R. C. Biedrzycki, and S. Firinciogullari, "Reliability and validity of the apathy evaluation scale," Psychiatry Research, vol. 38, no. 2, pp. 143-162, 1991.

[62] U. Lueken, U. Seidl, L. Valker, E. Schweiger, A. Kruse, and J. Schroeder, "Development of a short version of the apathy evaluation scale specifically adapted for demented nursing home residents," The American Journal of Geriatric Psychiatry, vol. 15, no. 5, pp. 376-385, 2007.

[63] E. K. Mahoney, A. C. Hurley, L. Volicer et al., "Development and testing of the resistiveness to care scale," Research in Nursing \& Health, vol. 22, pp. 27-38, 1999.

[64] M. L. Campbell, "Psychometric testing of a respiratory distress observation scale," Journal of Palliative Medicine, vol. 11, no. 1, pp. 44-50, 2008.
[65] S. L. Mitchell, J. M. Teno, D. K. Kiely et al., "The clinical course of advanced dementia," The New England Journal of Medicine, vol. 361, no. 16, pp. 1529-1538, 2009.

[66] L. Volicer, A. C. Hurley, and Z. V. Blasi, "Characteristics of dementia end-of-life care across care settings," American Journal of Hospice and Palliative Medicine, vol. 20, no. 3, pp. 191200, 2003.

[67] M. C. van Soest-Poortvliet, J. T. van der Steen, S. Zimmerman et al., "Psychometric properties of instruments to measure the quality of end-of-life care and dying for long-term care residents with dementia," Quality of Life Research, vol. 21, no. 4, pp. 671684, 2012.

[68] L. Volicer, A. C. Hurley, and Z. V. Blasi, "Scales for evaluation of end-of-life care in dementia," Alzheimer Disease and Associated Disorders, vol. 15, no. 4, pp. 194-200, 2001.

[69] B. Z. Aminoff, E. Purits, S. Noy, and A. Adunsky, "Measuring the suffering of end-stage dementia: reliability and validity of the mini-suffering state examination," Archives of Gerontology and Geriatrics, vol. 38, no. 2, pp. 123-130, 2004.

[70] S. J. Smith, "Providing palliative care for the terminal Alzheimer patient," in Hospice Care for Patients with Advanced Progressive Dementia, L. Volicer and A. Hurley, Eds., pp. 247-256, Springer, New York, NY, USA, 1998.

[71] D. K. Kiely, L. Volicer, J. Teno, R. N. Jones, H. G. Prigerson, and S. L. Mitchell, "The validity and reliability of scales for the evaluation of end-of-life care in advanced dementia," Alzheimer Disease and Associated Disorders, vol. 20, no. 3, pp. 176-181, 2006.

[72] A. A. Skolnick, "Medicaring project to demonstrate, evaluate innovative end-of-life program for chronically III," The Journal of the American Medical Association, vol. 279, no. 19, pp. 1511$1512,1998$.

[73] M. J. Barry, E. Walker-Corkery, Y. Chang, L. T. Tyll, D. C. Cherkin, and F. J. Fowler, "Measurement of overall and diseasespecific health status: does the order of questionnaires make a difference?" Journal of Health Services Research and Policy, vol. 1, no. 1, pp. 20-27, 1996.

[74] A. Jordan, C. Regnard, J. T. O’Brien, and J. C. Hughes, "Pain and distress in advanced dementia: choosing the right tools for the job," Palliative Medicine, vol. 26, no. 7, pp. 873-878, 2012.

[75] M. L. De Roo, J. T. van der Steen, F. Galindo-Garre et al., "When do people with dementia die peacefully? An analysis of data collected prospectively in long-term care settings," Palliative Medicine, vol. 28, no. 3, pp. 210-219, 2014. 


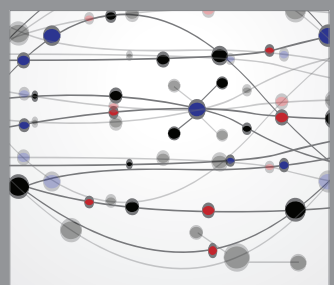

The Scientific World Journal
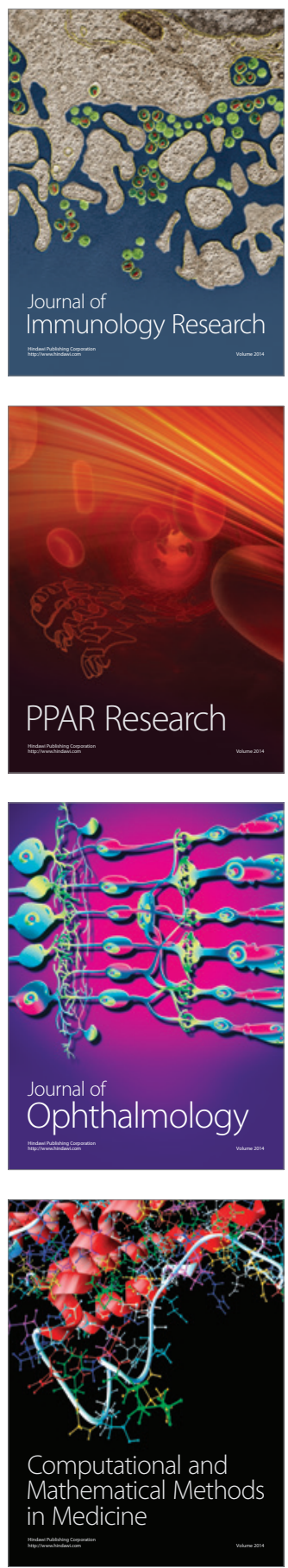

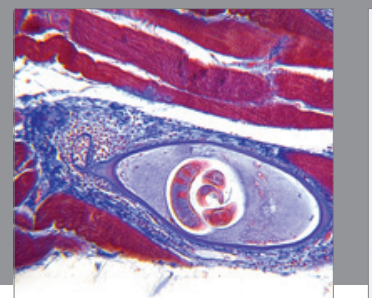

Gastroenterology

Research and Practice
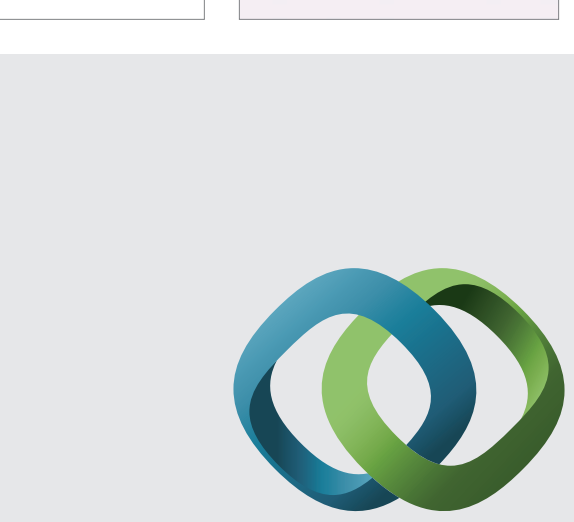

\section{Hindawi}

Submit your manuscripts at

http://www.hindawi.com
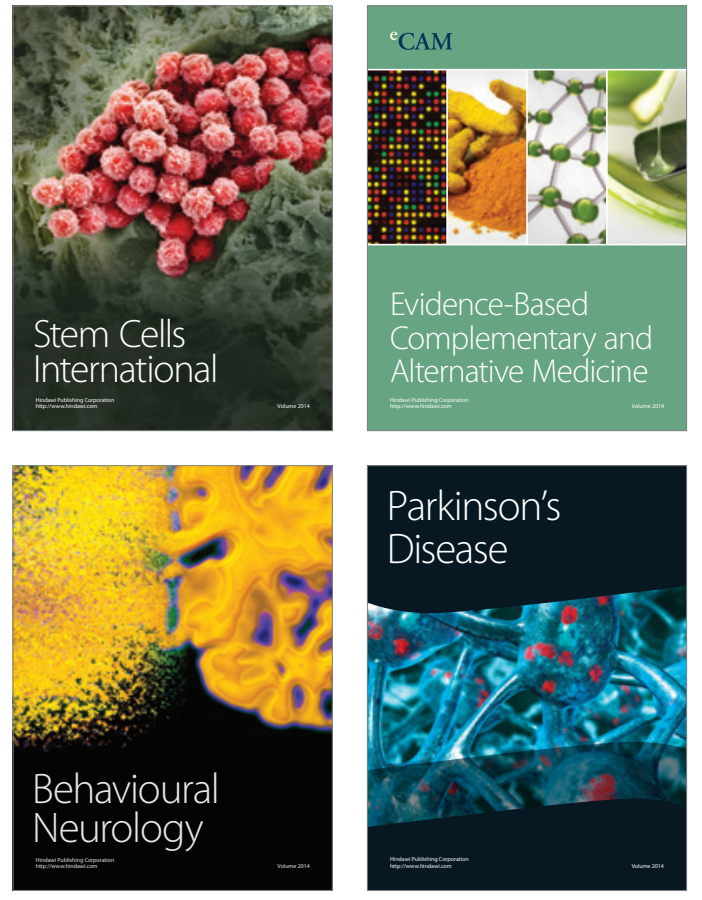
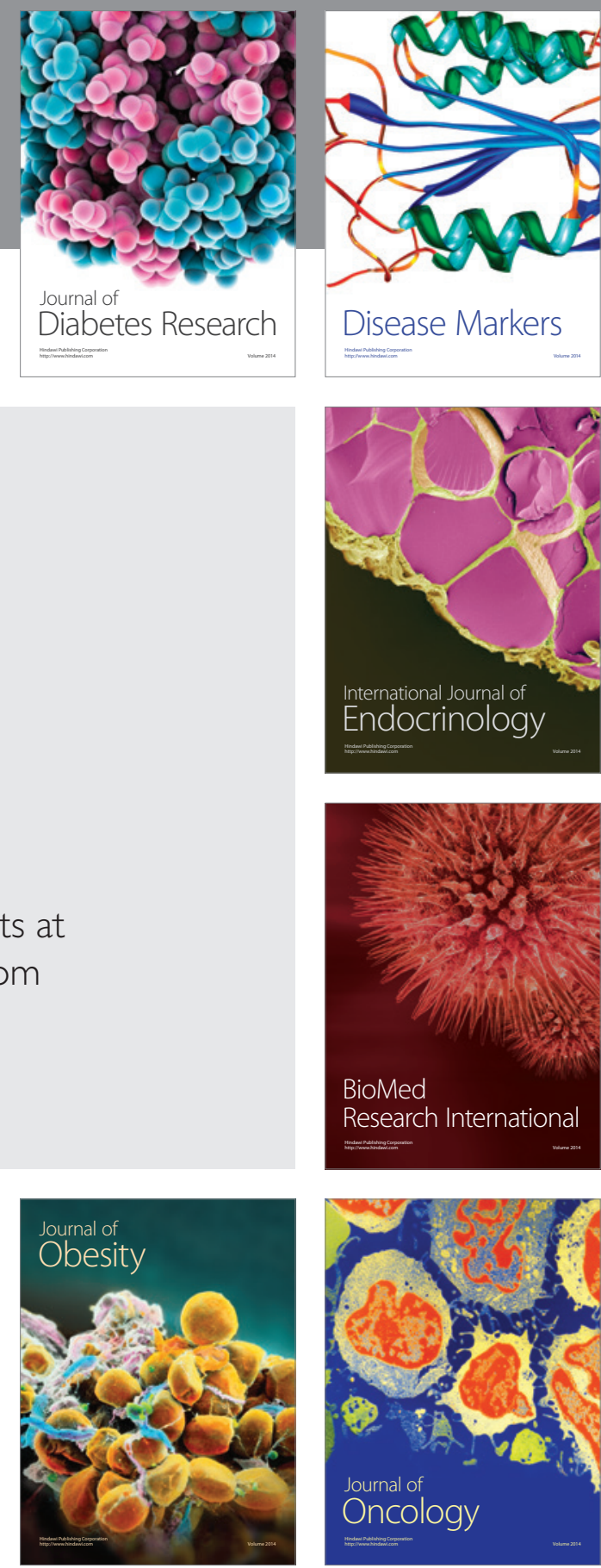

Disease Markers
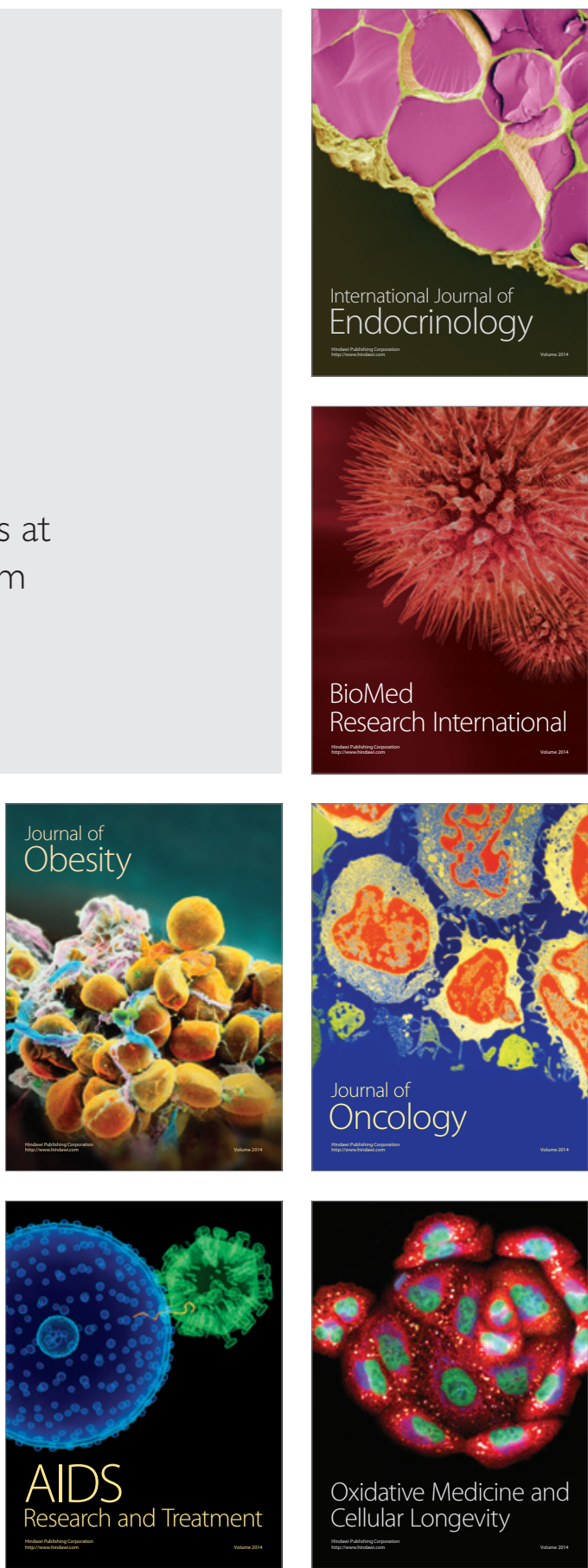